\title{
Contactos del Mediterráneo oriental EN EL SUROESTE DE LA PENÍNSUla IBÉRICA DURANTE loS SIGLOS XIV-VIII A.C. ¿MARINOS ORIENTALES O FENICIOS ATEMPORALES?
}

Francisco Gómez Toscano ${ }^{1}$

Universidad de Huelva ${ }^{2}$

Recibido: 04/02/2013

Aceptado: 06/02/2013

Revisado: 05/02/2013

Publicado: 17/06/2013

\section{RESUMEN}

Como refutación de posturas extremas que intentan mantener la explicación de la Protohistoria del Suroeste de la Península Ibérica desde presupuesto generados hace medio siglo, que han hecho a fenicios atemporales responsables de todos los cambios que experimentará la sociedad occidental, de forma sintética se analiza cómo se intenta asimilar el término fenicio con todos los orientales que se relacionaron con Occidente desde el II Milenio a.C. De la misma manera, por su relativa importancia para dicha explicación, se reivindica a través del registro arqueológico la existencia de un Bronce Final local previo a la presencia fenicia, tanto en el puerto atlántico de Huelva como en El Carambolo.

\section{Palabras Clave}

Contactos, Cananeos Fenicios, Occidente, Huelva, Carambolo

\section{ABSTRAC}

As the refutation to extreme positions clearly issued to maintain Southwestern Protohistory in terms evolved through the last half a century, which try to consider timeless Phoenicians responsible of the whole changes experienced by local western society as from the II Millennia BC is hereby synthetically analyzed. Also, by its relative importance for further explanations, following the archaeological records, the existence prior to Phoenician's arrival of a local Late Bronze society in the Atlantic Port of Huelva and in El Carambolo is also claimed.

\section{KEYWORDS}

Contacts, Canaanites, Phoenicians, Farwest, Huelva, El Carambolo

1 fgomez@uhu.es. Departamento de Historia I. Avda. Fuerzas Armadas s/n. 21007 Huelva.

2 Este trabajo se enmarca en el Proyecto de Investigación Análisis de la implantación y evolución del fenómeno urbano en el Suroeste peninsular: Arqueología Urbana en la Ciudad de Huelva, II ${ }^{a}$ Fase” (Ministerio de Ciencia e Innovación. Ref HAR200804666-HIST) perteneciente al Plan Nacional de I+D. 
El debate actual de la Protohistoria del Suroeste Peninsular.

En los últimos años, para el período comprendido entre los siglos finales del II Milenio a.C. y los cinco primeros del milenio siguiente, los avances obtenidos en el estudio del Mediterráneo en general permiten explicar la Protohistoria de la Península Ibérica desde presupuestos no valorados anteriormente, en especial por el escaso interés que una parte de los especialistas españoles ha prestado a las novedades aportadas por la investigación más allá de nuestro entorno occidental. Esta aseveración puede comprobarse con facilidad si analizamos la bibliografía que se cita en algunas contribuciones recientes, en las que bien se remite a antiguos manuales traducidos al castellano en el caso de comentar algún tema relacionado con el proceso histórico del Próximo Oriente, o bien se citan obras específicas para paralelizar elementos arquitectónicos descubiertos y excavados en Occidente, tales como un edificio con planta cuadrada o rectangular, o se compara la adscripción cultural de algún artefacto, en ambos casos sin prestar demasiada atención al contexto histórico o arqueológico de cada ejemplo, pero en especial de su cronología; lo importante es que tengan un cierto parecido formal o al menos aparente en tierras de los fenicios que sirva como paralelo.

De esta manera, parece fácil comprender que, en ocasiones, no sean todavía numerosas, y menos bien acogidas, interpretaciones basadas en planteamientos originados a partir de la abundante bibliografía que ahora modifica, aclara o mantiene interpretaciones del proceso histórico mediterráneo del pasado, las cuales han condenado a ser obsoletas importantes tesis previas que ahora resultan inadecuadas, al haber estado basadas éstas en la reconstrucción de la Historia general a partir de textos escritos muchos siglos después de los hechos que se narran, pero que la investigación pretérita las hacía prácticamente irrefutables dada la validez que simplemente se les reconocía. Como indicaba hace unas décadas Sabatino Moscati (1988: 24), con el tiempo se ha pasado de lo ambiguo a la suposición, y más que tesis expuestas lo que se observan son teorías presupuestas.

En esta línea argumental, parece claro que son los avances de la Arqueología moderna los que permiten trabajar ahora con datos objetivos frente a la subjetividad que pudo dimanar de la intención de los autores clásicos, sometidos a demasiadas tensio- nes políticas, económicas e incluso de pensamiento o de vinculación sociocultural del momento, pero principalmente porque el interés de la mayor parte de ellos no era estrictamente histórico, sino que en los textos se redactaron o en ellos se incluyeron demasiadas cuestiones que tal vez nos impidan entender sus fundamentos. Quizá, en realidad, los cambios no interesan demasiado porque, por comodidad, ha bastado citar a un clásico para que se aceptara una interpretación, como si fuera el veredicto irrefutable dictado por un juez.

Lo que nos parece más importante es que se hayan llegado a simplificar algunas explicaciones históricas en demasía, en especial a la hora de esclarecer a lo largo del período antes mencionado el origen de las influencias orientales que cada vez se observan en número creciente en el conjunto mediterráneo (Stampolidis, 2003) y especialmente en la Península Ibérica (Celestino y otros, 2008), pues, en algún caso, siguiendo paradigmas preconcebidos y aceptados décadas atrás, se ha adjudicado a los fenicios el papel de transmisores exclusivos de esas atribuciones, aunque siguiendo planteamientos largamente aceptados por la investigación. Pero para esos fenicios debemos estimar un tiempo claro y específico; no pueden seguir siendo una irrealidad temporal.

Como se verá más adelante, no es nuevo que todavía se destaque con ese término a unas gentes orientales que, entre otras bondades supuestas, o mejor es decir presupuestas como expresaba S. Moscati, no solo navegaron fácilmente por el Mediterráneo con barcos de vela y remos inventados y diseñados por ellos, construidos por primera vez con cuadernas y forro sobre un armazón de quilla, roda, codaste y baos de cubierta ${ }^{1}$, sino que también innovaron una nueva forma de comercio que se impondrá durante la Edad del Hierro en contraposición al tipo de intercambio aristocrático de la Edad del Bronce. Además, se les considera responsables de la distribución mediterránea y atlántica del hierro ${ }^{2}$, la de la escritura alfabética, y de tantas novedades que las poblaciones previas mediterráneas aceptaron sin aportar demasiado al imparable y generalizado proceso de cambio y de adaptación a las nuevas exigencias generadas a lo largo del proceso histórico, especial-

1 Como ejemplo previo puede compararse el pecio de Uluburun, un barco del II Milenio que ya fue construido con esas características quinientos años antes (Pulak, 1998).

2 Para comprobar la bibliografía de artefactos en hierro frecuentes en las Veiras portuguesas consultar R. Vilaça (2006; 2008). 
mente el comprendido entre la Edad del Bronce y la Edad del Hierro. En esta línea, aunque con importantes matizaciones según los casos, podríamos citar a autores tan relevantes como F.E. Movers (1841), G. Rawlinson (1889), W.B. Fleming (1915), R. Carpenter (1958), D. Harden (1963), M. Tarradell (1963), W. Culican (1966), H.J. Katzenstein (1973), S. Moscati (1983) o M.E. Aubet (1987).

En primer lugar, es evidente que los fenicios serían gente originaria de Fenicia, un espacio con unos límites geográficos que variarán dependiendo de cada período, aunque siempre en la estrecha franja costera que se extiende al norte de IsraelPalestina. Esos límites alternarán entre la bahía de Haifa al sur y otros accidentes geográficos al norte, como la desembocadura del río Narh el-Kelb en el período de apogeo de Tiro (Aubet, 2009), o a fines del siglo VIII a.C. con la crisis debida a la nueva política asiria y la independencia de Sidón, cuando se ampliarían por el norte hasta el curso de río Litani (Herrera y Gómez, 2004). A estos fenicios atemporales se les hace descender directamente de los cananeos de la Edad del Bronce, los cuales son citados en un territorio mucho más amplio y prácticamente abstracto, que en general se sitúa al norte de Egipto $^{3}$, fundamentalmente en la zona más cercana de la costa. Por ello, se ha creído que cananeos, fenicios, y también púnicos posteriormente, serían la misma gente pero estimada en momentos históricos sucesivos y en espacios territoriales y geopolíticos bien distintos. La realidad histórica tuvo que ser otra, según muestra el registro históricoarqueológico actual y así debemos estimarlo.

En diferente períodos, estos cananeos-fenicios aparecerán citados desde Ugarit al norte y la bahía de Haifa al sur, incluyendo entre otras a las ciudades de Biblos, de Tiro o de Sidón, las cuales serán consideradas la hegemónica de un momento dado, o al menos diferenciable o superior a las demás por una momentánea y relativa importancia política, económica o comercial. Sin embargo, Tiro será exclusivamente la metrópolis que enarbolará el pabellón responsable de la paradigmática Colonización Fenicia de Occidente a partir de la cita de V.

3 En recientes trabajos y en la transición del Bronce al Hierro, entre estos cananeos deben incluirse a gentes que después formarán parte del estado israelita (Ganor, 2009), dado que los estados de la Edad del Hierro son anteriores a su consideración como estados étnicos (Joffe, 2006), que es la que subyace en los textos históricos posteriores y que la investigación ha adjudicado.
Paterculo para la fundación de Gadir (Frutos, 1991: 16; Stampolidis, 2003; Aubet, 2006; 2008), y su conclusión posterior se adjudicará a unos púnicoscartagineses que sucesivamente representarán en el Mediterráneo central y occidental a los cananeos y a los fenicios, sin tener en cuenta las diferencias políticas, territoriales o temporales que representan los cuatro calificativos ${ }^{4}$, especialmente porque la tardía notoriedad -textual- de Cartago viene dada mucho más tarde por su enfrentamiento con Roma.

Por todo lo anterior, resulta claro que, para evitar problemas de fondo, algunos sectores de la investigación han aprendido hábilmente a valerse de esos agentes atemporales para explicar el proceso de orientalización que experimentó la sociedad occidental desde el II Milenio a.C., calificando de fenicias todas las influencias orientales detectadas en las últimas décadas por la Arqueología a partir de elementos de cultura material, los cuales, por su cronología previa, no pueden adscribirse a priori como es habitual a los fenicios históricos posteriores a Hiram I de Tiro, o al menos a los que así deberán considerarse, es decir, unas gentes perfectamente definidas en un tiempo y en su espacio histórico adecuado como aquí estamos demandando.

Sin embargo, como veremos más adelante, nos parece mucho más grave que en la Protohistoria peninsular, frente a una cuestionable atribución tartésica que se hacía de los materiales orientalizantes conocidos en los años cincuenta del pasado siglo (García y Bellido, 1960: 44, Blanco, 1956; 1960), ahora esos materiales y otros semejantes quieren hacerse otra vez exclusivamente fenicios, fabricados por y para esa clase preponderante y dominadora de los indígenas, para así poder negar la existencia en el Suroeste de ocupación local previa del Bronce Final y su continuidad a partir de la manipulación de las evidencias con que se cuenta, o al menos que parezca que la ocupación local previa, si es que la hubo, ésta era irrelevante.

4 Para la presencia de europeos en América, no será lo mismo citar asentamientos vikingos, castellanos, portugueses, ingleses, holandeses o franceses, como tampoco más tarde indagar en la presencia de italianos o irlandeses entre las comunidades norteamericanas del siglo XX. Todos serían europeos desde nuestro punto de vista actual, pero en el momento de su presencia en América Europa no existía. Las diferencias son sustanciales y todo no puede explicarse desde el viaje de Cristóbal Colón a fines del siglo XV.

5 Con las reticencias de M. Almagro Basch (1981: 68; Mederos, 2004: 37). Una evolución del concepto orientalizante y amplia bibliografía puede verse en J.M. Blázquez (2005). 
Incluso, tal como ahora estamos empezando a entender el proceso histórico y cómo debió gestarse la orientalización de la sociedad occidental del final de la Edad del Bronce y su gradual inclusión en el mundo mediterráneo, debemos diferenciar entre elementos orientales importados y los que han de adjudicarse a la sociedad oriental asentada ya en el conjunto del territorio occidental (Gómez, 2009), que mejor que fenicios, a secas, deben definirse como fenicios occidentales, en especial para diferenciarlos no solo de cómo ésta se va a desarrollar en Oriente a partir de ese momento, sino también de la sociedad local orientalizada a pesar de sus posibles semejanzas; tal vez fuesen esos tartesios mencionados en las fuentes griegas que ha barajado la investigación.

Debemos recordar aquí, en este sentido, que las diferencias en cultura material entre Oriente y Occidente en algunos momentos son bastante claras, pues las formas cerámicas generadas en Occidente en el último cuarto del siglo VIII a.C., como los platos de engobe rojo bruñido, pongamos por ejemplo, nunca se han documentado en la costa siro-palestina, ni antes ni después de ese final del siglo VIII a.C. (Lehmann, 1998), y el resto del repertorio diferirá de tal forma que parece que a partir de esa fecha los fenicios de Occidente no conocieron las formas típicas de la antigua zona metropolitana, como si por cualquier causa se hubieran interrumpido los contactos y, como es lógico esas producciones no son fenicias (Gómez, 2004: 91). Por todo ello, al ser pues los fenicios una definición generalizada por la investigación desde el siglo XIX, debemos incidir en cómo explicarlos en la actualidad.

\section{¿QUIÉNES FUERON LOS FENICIOS ATEMPORALES?}

Como ejemplo, frente a la escasez de datos escritos y la tardía mención en las fuentes antiguas en general, el desconocimiento de los fenicios históricos por Homero parece evidente a partir de la información que proporciona el texto transmitido, realmente cargado de tópicos creados por la sociedad griega del momento, los cuales deben relacionarse tanto con la propia elaboración como también con la transmisión de los poemas hasta la actualidad, cuando ahora el debate fundamental es saber si se debe aceptar su validez, pues el alcance histórico no puede negarse (Aubet, 2003: 86).

En general, en el esquema que aquí se debate, se ha estimado que los fenicios de la Edad del Hierro fueron la continuidad de los cananeos de la Edad del Bronce (Aubet, 1987: 8; Röllig, 1983; 1995: 213). Pero Canaán, independientemente de unos límites ajustados a cada período como se ha visto más arriba, solo es la antigua y ambigua denominación de una provincia o posesión territorial egipcia que se situaba al norte de Siria-Palestina (Dongen, 2010: 477 ), entre la costa mediterránea y el valle del río Jordán, con supuestos límites entre la Franja de Gaza al sur y el río Orontes al norte.

Se trata entonces de un territorio mal delimitado, relativamente fértil, aunque con apreciables diferencias entre las llanuras costeras al oeste y las más montuosas al este, que no incluye a las zonas desérticas situadas más allá de $100 \mathrm{~km}$ de la costa. Como es lógico, las amplias diferencias medioambientales existentes en el territorio darían lugar a gentes bien diferenciadas o bien semejantes en diversos aspectos.

Por tanto, en su día, el término Canaán incluía algunas porciones de las actuales Israel, Palestina, Jordania, Siria y Líbano. Era el lugar donde se encontraban los puertos de los comerciantes o navegantes mediterráneos durante la Edad del Bronce y en momentos posteriores de la Edad del Hierro (Dever, 1989: 107-108.), que ya serán los fenicios históricos mencionados por los autores clásicos. Ello implica, aunque solamente sea una suposición enmarcada en cada contexto, que los comerciantes semitas de la costa siro-palestina fueran primero cananeos y después fenicios, puesto que el término cananeo podría asimilarse en general a comerciante, una denominación que se perdería cuando Egipto dejó de hegemonizar la costa siro-palestina y de ejercer su poder sobre las gentes que la poblaban (Weinstein, 1992; Dongen, 2010: 477), como ya se observa en el texto de Unamón (Aubet, 1987: 303$307)$, prácticamente un siglo después del inicio de la crisis egipcia.

En relación con la continuidad de la Edad del Bronce en el espacio en cuestión (Gitin y otros, 1998), parece claro que ésta está asegurada en importantes núcleos de población de la antigua $\mathrm{Ca}-$ naán a partir de la denominada Crisis del 1200 a.C. (Ward y Joukowsky, 1989), tales como Arvad, Sidón, Tell Abu Hawam o Tiro (Bikai, 1989: 132; Herrera y Gómez, 2004), especialmente esta última a partir de la única excavación practicada en la antigua isla (Bikai, 1978: 74), pero sin duda esa continuidad debemos matizarla en una escala muy particular de acuerdo con cada uno de los casos (Stieglitz, 1990), en especial porque la informa- 
ción histórica de la que se dispone para los siglos XIII-XII a.C. es prácticamente nula, y poco más clara para los siguientes XI-X a.C., a no ser el citado texto de Unamón, y algún que otro contexto arqueológico siempre explicado desde el paradigma bíblico.

Entre otros nombres de gentes de la zona, en las inscripciones de Medinet Habu y en otros textos, se reconocen los términos de tipo étnico, posiblemente fenicios o mejor sería decir cananeos por su cronología, de los Fenkhu como uno de los enemigos asiáticos de Egipto que vivía al norte, y de los Hau-nebut, tal vez de la misma zona, relacionados ambos con Fenicia (Bikai, 1989: 135). En realidad, la inclusión de estos términos en textos que únicamente describen a gentes del norte allende el mar, los sea peoples de esos textos egipcios, no ayudan demasiado a la hora de identificar una procedencia específica ${ }^{6}$. Entre estos últimos, los filisteos, parece comúnmente aceptada su procedencia egea a través de Chipre, observable en su cultura material en los inicios de su presencia a partir de ca. 1200 a.C., los cuales mantendrán su preponderancia sobre los cananeos originales de la zona para conformar un nuevo estado étnico durante la Edad del Hierro (Finkelstein, 2007), pero, principalmente, será el contraste con los hebreos lo que reforzará la etnicidad de cada uno, al menos hasta el Hierro II (Faust y Lev-Tov, 2011: 20-23), momento en que las posturas se acercarán mutuamente dando lugar a que, además, se pierdan algunos de los aspectos que los diferenciaba. De la misma forma, el término Habiru, que aparece como sinónimo de problemas y rebeliones, ha podido relacionarse con hebreos, aunque no resulta claro si únicamente sería una denominación de tipo social o específica más que una etnia (Na'aman, 1986), que ya serían los israelitas históricos. Parece claro, sin embargo, que algunos de los comerciantes de la zona se consideraban a sí mismos cna'ani (Sherratt, 1998: 307), pero ello no implica que formaran un país o un estado, pues podría tratarse también de una de las clases sociales que conformaban esas ciudades-estado multiétnicas indepen-dientes por definición.

Pero lo que debemos tener en cuenta en relación con el debate actual, es que la consabida etnicidad de los estados secundarios que se formarán a lo largo de la Edad del Hierro (Joffe, 2006), y no antes,

6 Se puede mencionar como identificación hipotética que su dios era Baal, como el de los Tjeker, otro pueblo del mar. incluyendo a los puertos o ciudades-estado fenicias (Röllig, 1983), es decir, hebreos, arameos, filisteos, moabitas, amonitas, edomitas o los fenicios de Tiro o Sidón - los tirios y sidonios pongamos por casose asume mucho después de su constitución como tales estados, por lo que desde una denominación generalizada, la cananea de la Edad del Bronce, amplia, ambigua, en parte enigmática y poco explícita como se ha visto, surgirá la base multiétnica de la que nacieron todos esos estados excepto el filisteo (Bauer, 1998), formado en principio por inmigrantes del Egeo y Chipre, aunque ese estado también lo integrarían antiguos cananeos indígenas de su zona específica, una realidad que solo será asumida como base cierta a partir de la Edad del Hierro, siempre de acuerdo con los autores clásicos y su particular noción o interpretación de la Antigüedad, aunque no podamos conocer en qué número, o en qué porcentaje. En realidad, los fenicios no son los únicos que descenderían de los cananeos, también lo fueron esos otros que conformaron los nuevos estados, que son los que van a reconocer y por ello transmitirnos los historiadores clásicos.

En cuanto a la génesis del nombre más comúnmente citado para los fenicios, los rojos por el color de la piel al ser marinos bañados por el sol y el salitre o el del tinte obtenido por ellos del murex, son trivialidades creadas por la investigación a lo largo de los siglos XIX y XX. Solo es una novedad importante para nosotros que esa denominación pueda relacionarse por su calidad de inventores con la escritura fonética al derivar su nombre en griego

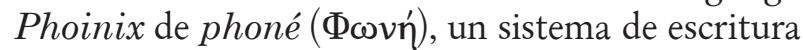
que sí fue trascendental para los griegos de la Edad Oscura, por lo que de ahí podría proceder el nombre con el que los conocemos (Ganor, 2009: 199).

En este sentido y por su relación con el mundo egeo, parece pues suficientemente claro, como ha mostrado M.E. Aubet siguiendo a Rowland (1980: 28), que la importancia dada a los fenicios fue por haber sido ellos los que pusieron en práctica las leyes del nuevo tipo de comercio que van a imponer en los lugares que frecuentaban y en los propios de sus ciudades costeras orientales y el Mediterráneo en general, incluso en Occidente, ya que, frente al comercio aristocrático de la Edad del Bronce, extensible al mundo mediterráneo en general pero representado por las gentes del Egeo, todavía en vigor en su Edad Oscura, el tipo practicado por los fenicios históricos ...amenaza las bases del control aristocrático sobre la producción local de excedente 
destinado al intercambio y mina el sistema de alianzas políticas basado en las relaciones de hospitalidad y de intercambio dentro de un sistema cerrado y autosuficiente (Aubet, 2003: 95), y los fenicios históricos rompieron esas bases tradicionales en su propio beneficio. De todas formas, en cada puerto de comercio que se conozca, deberá tenerse en cuenta la propuesta de J. Alvar (2008) para establecer cuál era la relación entre el componente indígena del lugar y los otros comerciantes que lo compartían, además de los fenicios orientales, que no siempre los hegemonizaban.

En concreto, nuestro conocimiento del proceso histórico en el Próximo Oriente viene dado por cómo se ha gestado su reconstrucción a lo largo del siglo pasado, y su aceptación prácticamente generalizada a partir de mediados de ese siglo. Como es lógico, creemos que no es pertinente ni contamos con el suficiente espacio en este trabajo para plantear con profundidad todo el proceso, pero, no obstante, sí es necesario hacer algún tipo de puntualización acerca del estado de la cuestión en el debate actual, relacionado claro está con la cronología absoluta -histórica- del Próximo Oriente, y hasta dónde puede vincularse a ésta con el texto bíblico, que quizá sirva para explicar qué y quiénes eran esos fenicios por su relación con el mismo, que es la principal fuente donde se mencionan. En realidad, será nuestra reflexión, la de cada uno en particular, la que nos lleve a explicaciones coherentes o incongruentes.

Del paradigma bíblico a la low Chronology de I. FinKELSTEIN.

De acuerdo con la situación actual, parece ya suficientemente perceptible que el paradigma bíblico que se debe a la genialidad del orientalista W.F. Albright, padre de la arqueología bíblica (Albright, 1954), creado a partir de la interpretación literal de los textos y al uso de los datos arqueológicos como prueba de los hechos históricos (Feinman, 2004), solo comenzará a perder su credibilidad a partir de la década de los noventa del pasado siglo XX. Hasta tal punto que, por la reconocida autoridad del investigador norteamericano, las nuevas corrientes teóricas de los años sesenta no influirían en el paradigma, ni siguiera en los métodos de excavación puestos en práctica en Israel, con lo que la historia bíblica continuará hegemonizando la explicación histórica del Próximo Oriente hasta que comienza a ser efectiva la combinación de la cronología ra- diométrica con las más modernas técnicas arqueológicas.

A partir de un artículo publicado por I. Finkelstein (1996), basado en su propuesta de una nueva low chronology que establecía para el Hierro II en Palestina, se comenzará a ser consciente que la $\mathrm{Bi}-$ blia no fue escrita realmente como libro histórico, sino que se trata de un relato artificial creado con fines religiosos en beneficio de la ideología de sus redactores ${ }^{7}$, por lo que la correlación con el registro arqueológico no podrá mantenerse como hasta ahora se había hecho, en especial si no existen coincidencias claras en ese registro que lo demuestren (Finkelstein, 1998; Finkelstein y Silberman, 2001; $2003)^{8}$.

Ese sesgo dado por la investigación viene dado porque, a partir de la década de los sesenta, prospecciones arqueológicas realizadas en todo el país daban como resultado un panorama que no aparecía reflejado en el texto bíblico. Principalmente no se confirmaba la existencia del reino unificado por David y Salomón (Finkelstein, 2010), sino que después de la aparición todavía en el II Milenio a.C. de nuevos asentamientos, muy pequeños en extensión, con menos de una hectárea y sin murallas, contrastaba con la continuidad de los grandes asentamientos conocidos desde de la Edad del Bronce (Finkelstein, 2006). Al mismo tiempo, la interpretación del contexto arqueológico de sitios paradigmáticos como Megiddo, Hazor o Geser, con sus impresionantes murallas y puertas salomónicas según la interpretación de su excavador (Yadin, 1958; Yadin y Ben-Tor, 1993), puede hacerse ahora a partir de la cronología relativa de sus materiales, especialmente de la evolución de la cultura material detectada en esos sitios y casi en la totalidad de los conocidos del momento. Esa cultura material, muy

\footnotetext{
7 En realidad, la Biblia sería un proyecto de creación de una monarquía expansiva y teocrática por Josías de Jerusalén y su círculo a fines del siglo VII a.C., en el que la minúscula capital de su reino de pastores y agricultores en la estéril y abrupta orografía de Judá tendría que ser el futuro centro político y religioso de todo Israel. Ver G. Puente Ojea, en prólogo a la versión española de The Bible Unearthen... (Finkelstein y Silbermann, 2007: 14).

8 Además de la aquí citada, está disponible una amplia bibliografía de I. Finkelstein y colaboradores, además de otra semejante debida a A. Mazar y colaboradores (2005, 2010, 2011, entre otros), relacionada con los dos tipos de cronologías imperantes - high y low- así como la de un gran número de investigadores más o menos independientes que pueden apoyar una $u$ otra, o relacionarse con cualquiera de los tópicos tratados.
} 
similar a la documentada en la Samaria fundada por Omri en los inicios del siglo IX a.C., construida en un promontorio no ocupado con anterioridad, también se documenta en otros ejemplos bien fechados con sistemas defensivos idénticos a los de la propia Samaria, como en Jezreel, Megiddo VA-IVB, Hazor X y Geser VII (Finkelstein y Lipschits, 2010: 32; Bodine, 2010), que por ello no podían ser anteriores.

A partir de ahí, puede decirse que en los últimos años se está escribiendo una nueva historia, basada fundamentalmente en el registro arqueológico del territorio en general y en la utilización de dataciones de $C_{14}$ (Finkelstein, 2008), en la que el texto bíblico no impone sus reglas tradicionalmente aceptadas como ciertas, sino que ésta tendrá que estar basada en datos arqueológicos contrastados (Finkelstein, 2011a), y el papel de los textos será otro. Desde esta perspectiva, entre otros tópicos, es posible explicar la evolución de Jerusalén pero solo desde el siglo IX a.C. (Finkelstein, 2001), la importancia de Samaria como la primera capital del reino norte fundada en ese mismo siglo (Finkelstein, 2011b), las primeras fortificaciones de Israel (Finkelstein, 2000) y de Judá (Finkelstein, 2012), o el paradigma creado en torno a los filisteos (Finkelstein, 2007; Finkelstein y Piasetzky, 2007). Además, a través de la cronología radiométrica, imprescindible para estimar los fundamentos históricos que surgieron de los abundantes estratos de incendio y destrucción, se verá que éstos no pueden adscribirse a un episodio histórico conocido y con las cronologías históricas preestablecidas para sustentarse con el optimismo anterior o, al menos, deben ser estimadas desde una oportuna crítica constructiva y una duda razonable (Finkelstein y Piasetzky, 2009).

Para el interés primordial de este trabajo, en relación con la presencia de los fenicios en Occidente, la mención de los barcos de Tarsis (I Reyes, 9: 26-28) puede considerarse ahora el principal punto de desencuentro con el paradigma bíblico. Si para la relación de Hiram I con Salomón en el siglo X a.C. no existen evidencias arqueológicas en el país de origen, difícilmente pudieron llegar allí barcos fenicios cargados de plata de Occidente en la primera mitad de ese siglo consignados a Salomón. Por el contrario, si el texto se escribió en momentos posteriores, tal vez en época de Josías de Jerusalén, a finales del siglo VII a.C. o con posterioridad, sí se pudo tener consciencia de una antigua Tarsis, solo un puerto en Occidente, de donde se asimiló hubie- se llegado en su día gran cantidad de oro, plata o marfil para engrandecer al mítico rey de Israel, el bendecido por su dios único.

Además de la relación con materiales fechados a partir de los inicios del siglo IX a.C. y fundamentalmente del siglo VIII a.C. (Gilboa y otros, 2009: 173), la publicación del reciente hallazgo de la marisma de Huelva ha querido valerse de la cronología radiométrica realizada a tres huesos de bóvidos hallados aparentemente en el mismo contexto (González y otros, 2006; 2008; 2010), que confirmaba lo ya publicado (González y otros, 2004), cuando, de hecho, esa datación fecha únicamente a los huesos y no a todos los materiales arqueológicos importados que erróneamente se han relacionado con ...la primera ocupación humana [de Huelva] (González y otros, 2004: 25), puesto que el puerto existía mucho antes, al menos desde finales del II Milenio a.C. (Gómez, 2009).

En el debate acerca de la importancia para la Península Ibérica de los fenicios, también las excavaciones realizadas desde el año 2002 en el Carambolo representan un importante punto de partida para discutir la denominación fenicia atemporal. Principalmente, según se desprende de los autores de los trabajos desde las primeras publicaciones, lo que se cuestiona es el interés por deconstruir el paradigma tartésico generado el pasado siglo para transformar al Carambolo desde asentamiento tartésico local a santuario fundado por los fenicios de Spal, no sabemos si con el interés final de haber encontrado un Tarteso fenicio en Sevilla.

De todo ello, entendiendo que la reconversión que se pretende de ambos asentamientos, tanto Huelva como el Carambolo, considerados hasta ahora los sitios paradigmáticos de la génesis y continuidad local, los inicios de ambos se quieran ahora relacionar con unos fenicios que, como hemos visto más arriba, necesitan ser definidos en un tiempo y en un espacio histórico tangibles, pues las dudas superan lo que se había aceptado como cierto. Será pues el análisis del conjunto publicado, que en el caso del Carambolo permanece prácticamente inédito, lo que permita establecer comparaciones con el registro arqueológico del Próximo Oriente y, de ahí, su cronología e integración en el contexto histórico correspondiente. En el caso de Huelva, como reflexión objetiva, si el importante hallazgo de las marismas se hubiese publicado un par de décadas antes no hubiese tenido ningún problema de credibilidad. Ahora ha llegado demasiado tarde. 
¿Continuidad de la Prehistoria Reciente o hiato Poblacional EN El Suroeste? La EVIDENCIA ARQueOlógica aCtual a través de Huelva y El Carambolo.

Si hasta la década de los ochenta el principal tópico de la Protohistoria del Suroeste fue la búsqueda de Tarteso (Maluquer, 1968), el resultado de su investigación sería el descubrimiento de los $f e$ nicios a partir de la cultura material detectada en los yacimientos estudiados en el Suroeste (Gómez, 1997). En efecto, durante las últimas cuatro décadas del pasado siglo, la investigación ha explicado el desarrollo protohistórico del Suroeste a partir de la existencia de un sustrato local de la Edad del Bronce, al que se incorporaron los fenicios en una fecha que, desde el 700 a.C. (Blázquez y otros, 1970: 11) iría adelantándose a medida que aparecieron paralelos de cultura material cada vez mejor fechados en origen. Sin embargo, mientras que nosotros adelantamos hace tiempo la cronología de los inicios del Bronce Final al II Milenio a.C. (Gómez, 1997), otras líneas de investigación todavía continúan mantenido la establecida en la década de los sesenta (González y otros, 2004), pero sí han adelantado la de los primeros fenicios para llegar a coincidir con la estimada existencia de un vacío poblacional en el Suroeste entre los II-I Milenios a.C. (Escacena, 2008), situado entre una pre-colonización oriental y la paradigmática colonización fenicia del siglo VIII a.C. (Gómez, 2004; Gómez y Fundoni, 2011), es decir que el Bronce Final, en su totalidad, tendría que ser prácticamente sincrónico con la presencia fenicia9. Ese 'prácticamente' se destaca al incluir la cronología de la Ría del Huelva en el siglo IX a.C. de acuerdo con las dataciones de $\mathrm{C}_{14}$ pero tal como fue establecida en el momento en que se realizaron los análisis (Almagro, 1977), y se compara con la de otras, pero calibradas, obtenidas de huesos rescatados de la marisma fuera de su contexto original (González y otros, 2006; 2008), para hacerlas 'prácticamente' del mismo momento, aunque, en realidad, al menos puedan estar separadas por un siglo de acuerdo con la teórica amplitud radiométrica, y mucho más por las diferencias crono-tipológicas tradicionales que se observan en el registro arqueológico.

En el caso de la Marisma de Huelva, por su relevancia a la hora de establecer posibles comparaciones con la cronología del Próximo Oriente, en

9 Una circunstancia similar, apoyada por dataciones radiocarbónicas, se observa en una de las interpretaciones recientes de El Carambolo (Fernández y Rodríguez. 2007: 253 y ss.) especial con el reinado de Salomón y el episodio de las naves de Tarsis (1 Reyes, 10, 22), ha sido utiliza$\mathrm{da}$, junto con otros sitios del Mediterráneo, como base para mantener la cronología alta oriental y la veracidad histórica de la Biblia (van der Plicht y otros, 2009: 226). Esa interpretación recibió una fuerte pero amable crítica por parte del equipo de I. Finkelstein, que se fundamentaba tanto en el uso problemático que se hacía de las dataciones radiocarbónicas como en la calidad del registro arqueológico que se asumía, en especial porque entienden que los huesos analizados y el conjunto de los materiales estudiados no son de un ...clear archaeological stratum... como preconizan tanto los autores del hallazgo en Huelva como el equipo de la Universidad de Groningen (Fantalkin y otros, 2011: 184).

En cuanto al uso de la datación de los bronces de la Ría (Nijboer y van der Plicht, 2006; van der Plicht y otros, 2009) se utiliza la cronología alta de A. Mazar para fechar la fíbula de Megiddo y hacer las del conjunto onubense importaciones orientales o, al menos, tipos de génesis fenicia, cuando ya sabemos que la cronología de las primeras fíbulas tipo Huelva es anterior al siglo $\mathrm{X}$ a.C. como el resto de bronces del fondo de la Ría (1050-950 a.C.), una circunstancia que confirmaría la presencia en Chipre del asador de Amathus (Torres, 2008; 2012: 463), así como la tipología de las fíbulas y su dispersión en la Península Ibérica, puesto que las de Huelva no serían las más antiguas (Carrasco y Pachón, 2006). Cualquier elemento localizado en el registro oriental no tiene por qué ser una producción local y nunca debe desdeñarse la posibilidad de que sea un elemento llevado desde el lejano Occidente. A pesar de ello, esta crítica también ha tenido su respuesta por parte del equipo holandés (Bruins y otros, 2011: 213), estimando que hace falta contar con más dataciones, contextos arqueológicos claros y, por supuesto, no estar de acuerdo con los planteamientos de la low chronology, con lo que el debate continuará durante un tiempo.

Desde nuestro punto de vista, nos parece importante reconocer que el meollo del problema se encuentra en la estimación lógica del conjunto de hallazgos publicados y su categoría históricoarqueológica. Sin cualquier duda, ni los materiales representan un único período histórico, ni fueron hallados en un claro estrato arqueológico; se ha estimado así (González y otros, 2004: 25), pero no es el caso. 


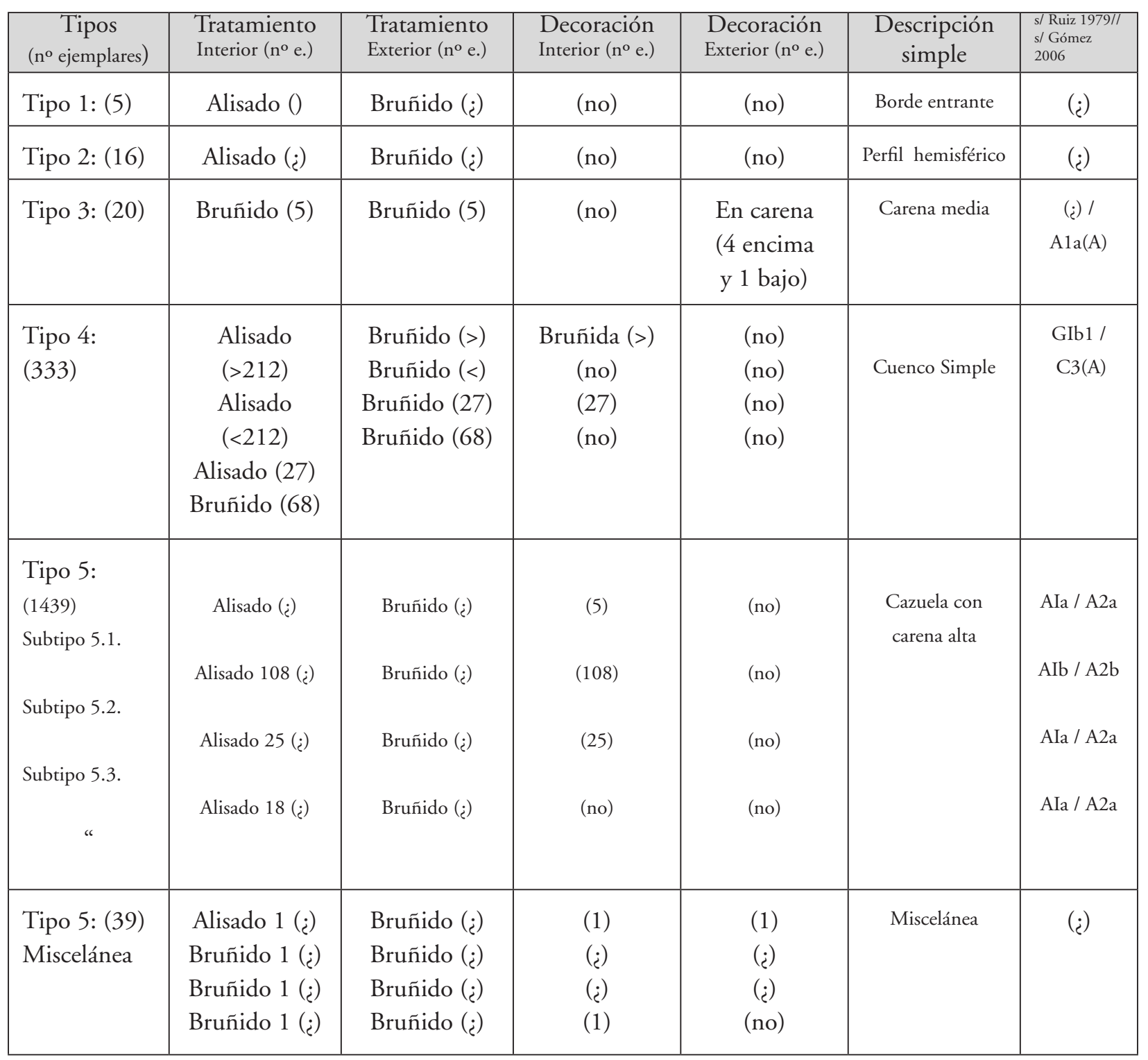

Figura1. Cuencos en cerámica local recogidos en la marisma de Huelva (González y otros 2004). Decoraciones bruñidas sobre bruñido del galbo interior pertenecientes al Horizonte Formativo (1200-1000 a.C.) aparecen en 5 ejemplares del Tipo 3; del Tipo 4 un 30\% presenta decoración bruñida sobre interior del galbo bruñido; del Tipo 5 solo se menciona que en ocasiones ambas superficies aparecen bruñidas y la decoración es seudoacanalada; del Tipo $5 \mathrm{~m}$ un $25 \%$ presenta decoración bruñida sobre interior del galbo bruñido. Faltan los cuencos con carena alta A3a conocidos en Huelva en su Horizonte Residual, posterior al 750 a.C. (Gómez 2006).

Como ya hemos mencionado en varias ocasiones (Ruiz Mata y Gómez, 2008: 340), se trata de un conjunto de materiales recolectados en las marismas de Huelva, a donde fueron transportados y descargados con camiones después de haber sido retirados de su contexto original excavados con maquinaria pesada ${ }^{10}$; lógicamente ni la retirada de su

10 Los fragmentos publicados, tal como pueden verse en lugar de origen ni la descarga en la marisma fueron controladas por arqueólogos, sino que, de forma

el Museo Provincial de Huelva, no pudieron estar situados en un sedimento correspondiente a niveles de ocupación, puesto que su escasa fragmentación y deterioro nunca se observan en niveles antropizados, los walk on levels de la terminología anglosajona. Tanto esas características como la transformación del color rojo en las cerámicas tirias de importación nos llevan a estimar se trata del espacio intramareal del puerto. 


\section{Huelva. Evolución de la cerámica del Bronce Final y su relación con el Mediterráneo}

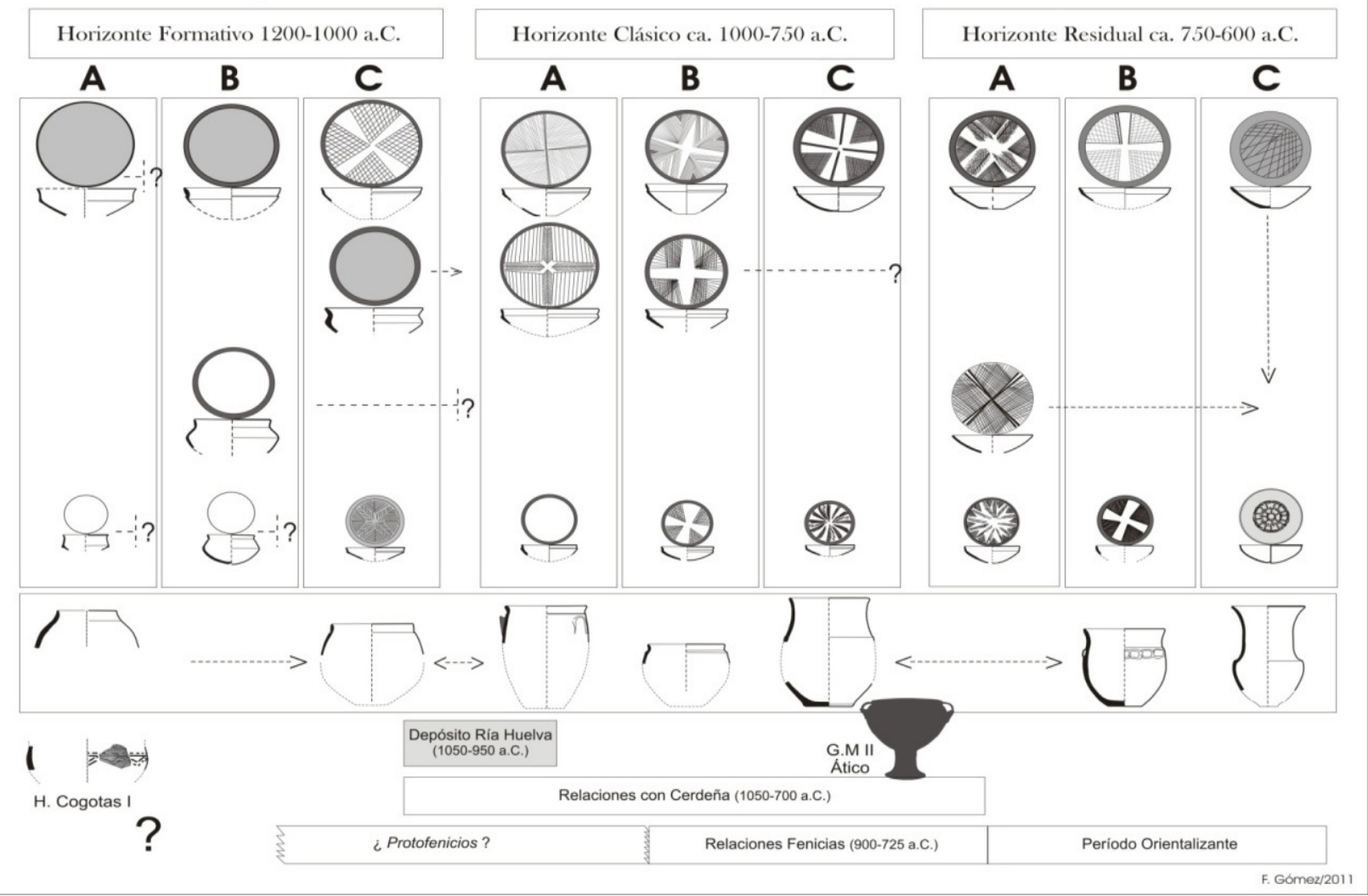

Figura 2. Evolución de las cerámicas del Bronce Final en Huelva: Horizontes Formativo, Clásico y Residual, y su relación con los contactos orientales.

aleatoria y a conveniencia exclusiva de los transportistas, fue amontonado en lugares diferentes de un amplio espacio marismeño y de allí rescatado y estudiado a lo largo de varios años. Ni siquiera sabemos cómo estarían depositados los materiales, a no ser que se ha dicho que aparecían manchados de barro negruzco. ¿Pero se mancharon antes o después de ser extraídos, transportados y descargados cada uno de ellos? No podemos negar aquí, no sería justo, como también hemos mencionado en otros sitios anteriormente, que los autores de la publicación realizaron un estudio casi perfecto de todo el conjunto pero, por cualquier razón que no entendemos, soslayaron aclarar al detalle la procedencia y el método seguido, restando así credibilidad al trabajo en función de que surja una duda razonable en la interpretación de algún tópico.

Entendemos que el principal problema es estimar la cronología radiométrica de los huesos como indicador de cronología absoluta de todos los mate- riales. No vamos a entrar aquí en un debate generalista de los materiales importados, pero, dentro del conjunto, inadvertidamente, se han publicado cerámicas locales que pueden ser, incluso, del II Milenio a.C., pues si observamos la Figura 1, donde aparecen todas las formas a mano de cazuelas y cuencos publicadas, por su decoración bruñida sobre el galbo interior bruñido, algunos ejemplares deben adscribirse a nuestro Horizonte Formativo del Bronce Final de Huelva (Figura 2), que hemos estimado comienza ca. 1200 a.C. y finalizaría en el cambio de los II-I Milenios (Gómez, 2008)11 , aunque debe existir una fase de transición entre ambos horizontes. Por ello, aunque no se han publicado tipos conoci-

11 Si remitimos a las bases cuidadas en cerámica local (González y otros, 2004:), en las del tipo 3 un 30\% también presenta decoración bruñida sobre interior bruñido, y las del tipo 4 hasta un $50 \%$, que aumenta el número de cerámicas locales de momentos prefenicios situadas erróneamente dentro del conjunto. 
dos del Horizonte Residual posteriores a mediados del siglo VIII a.C., sí se han incluido en el conjunto cerámicas locales de cronología previa a la presencia fenicia ${ }^{12}$, por lo que los huesos analizados que han dado lugar a las fechas radiométricas también podrían ser de ese momento anterior y no contemporáneos de la primeras cerámicas fenicias y de las geométricas griegas ${ }^{13}$. Así, a nuestro pesar, deberían desestimarse algunas de las interpretaciones asumidas por la investigación en los últimos años, especialmente las que han dado lugar a razonamientos y conclusiones a nuestro juicio inconvenientes (Antonelli, 2006; Brandherm, 2008), si la cronología del conjunto de materiales fuera la única base para estimar el cambio. Pero, principalmente, entendemos que a partir de las dataciones radiométricas de Huelva no puede asegurarse cualquier implicación en el debate de la cronología del Próximo Oriente, y menos que apoye la 'cronología alta' y la relación del reino unificado con Occidente.

A partir de las recientes excavaciones realizadas en El Carambolo, también hemos asistido a un intento vano de deconstruir la Protohistoria del Suroeste peninsular desde el paradigma fenicio, el cual ha sido ampliamente aceptado por muchos investigadores (De la Bandera y Ferrer, 2010). Para documentar el contexto donde apareció el famoso tesoro, en el único espacio entonces disponible, en octubre de 1958 se excavaron hasta alcanzar el nivel III dos zanjas aprovechando el hueco realizado por los obreros para rebuscar el hallazgo. A partir de allí y a algo más del metro de profundidad, el nivel IV, como la excavación mostraba rastros de fuego, huesos y trozos de barro endurecido con imprimaciones paralelas de palos o cañas ${ }^{14}$, este contexto se relacionó con la superestructura vegetal de un fondo de cabaña estratificado, y todo el nivel se excavó por capas horizontales hasta el sustrato estéril (Carriazo, 1980: 242).

El fondo tendría forma oval con ejes máximos de $6 \times 4$ '5 me fue la delimitación observada en

12 Se trata de un error lógico al considerar que todas las cerámicas del Bronce Final tenían que incluirse en un corto período del I Milenio a.C.

13 Se cuenta ahora con dos fechas radiométricas obtenidas en cabañas locales que representan la fase de transición entre los Horizontes Formativo y Clásico de Huelva (Beltrán y otros, e.p.), que apoyan la fase local de transición en ese momento.

14 Como se observa en la descripción de J.M. Carriazo, más que las cerámicas, los restos de una cubierta quemada y su contexto arqueológico fueron la base donde se apoyaba la definición de fondo de cabaña. ambas zanjas. El ajuar rescatado estaba formado por un conjunto de elementos metálicos, tales como dos puntas de flecha, barritas, aros, clavos, y también un masa amorfa de hierro (Carriazo, 1980: 268) ${ }^{15}$, molinos y moledera de mano, placa de arquero incompleta, un fragmento de sierra en cuarzo y otros útiles de sílex, muchos huesos de animales consumidos, conchas, fragmentos de huevos de avestruz quemados, un conjunto de fragmentos cerámicos prácticamente desconocido en esos momentos en el Suroeste ${ }^{16} y$, sobretodo, pellas de barro endurecido por el fuego con improntas de cañas, todo ello estructurado en finas capas superpuestas como se ha dicho. Este ajuar llevaría a considerar que los estratos más bajos del Carambolo Alto eran el resultado de la existencia allí de una cabaña protohistórica, que inmediatamente, al tratarse de materiales muy novedosos, fue relacionada con Tarteso, ese mundo mítico del que se desconocía su cultura material ${ }^{17}$.

En el informe del Dr. Maluquer, tal cual lo cita Carriazo, ...puede deducirse que la zona excavada comprende, por una parte, el interior de una vivienda o choza, que pereció en un gran incendio, quizás repetidas veces; $y$ por otra, una zona de vertedero exterior que probablemente estuvo al aire libre durante la vida de aquella casa. Al derribarse incendiada ésta, quedó marcada la oquedad dibujada por su perimetro, y comenzó a formarse lentamente un estrato de relleno, que llegó a regularizar la superficie. O bien se arregló artificialmente, para formar una plataforma sobre la que construir nuevas viviendas (Carriazo, 1980: 270).

A partir de 2002 se ha realizado una excavación en área para documentar la naturaleza del asentamiento, debido a que se pretendía urbanizar la zona.

15 Ya no es extraña ni a priori debe considerarse fenicia la presencia de hierro en el Bronce Final de acuerdo con el registro local. En este sentido puede verse Vilaça, 2006).

16 En la actualidad se cuenta con una amplia bibliografía del Bronce Final, incluso fechado con dataciones de $\mathrm{C}_{14}$ (Gómez, e.p.). Entre esa bibliografía remitimos a la aportación de García y Hurtado (2011) y, especialmente, la de J. Jiménez Ávila y Guerra Millán (2012), donde en Medellín se ajusta la cronología del Bronce allí representado desde los inicios al de la aparición de las cerámicas tipo Carambolo.

17 Entre los materiales recuperados, ...como es normal en los ajuares domésticos (Carriazo, 1980: 269), el predominio era de formas desconocidas y faltaban las que se definen por un pequeño fragmento, lo cual fue considerado un inconveniente, pero ratificaba la idea de ser el ajuar de una cabaña que en aquellos momentos no podía relacionarse con otro período histórico que no fuese el tartésico. 
En un primer trabajo publicado de esta campaña (Fernández y Rodríguez, 2005a), al no disponer de análisis radiométricos, se utilizan las cronología relativas con que se cuenta en esos momentos, se menciona un hiato de ocupación entre el Calcolítico final/Bronce inicial al Orientalizante inicial, y se describen las cinco principales fases del santuario.

En otro trabajo posterior, redactado también antes de finalizar la actividad de campo (Fernández y Rodríguez, 2005b: 842), se menciona la primera fase de ocupación según se ha dicho entre el Calcolítico final y un Bronce antiguo/medio ${ }^{18}$, representado por ...una serie de fosas de planta circular y elíptica y sección de tendencia esférica (Fernández y Rodríguez, 2005: 846), y no se descarta que existieran estructuras de habitación en esa primera fase. Lógicamente se resalta que entre esta fase prehistórica y el complejo monumental del santuario más antiguo habría un vacío en la ocupación hasta el siglo VIII a.C. (Fernández y Rodríguez, 2005b: 846). En relación con la cabaña del Bronce Final de Carriazo y Maluquer, excavada ahora completamente, se menciona que su contexto es paralelo a las fases III-IV del siglo VIII a.C. y, por ello, no se incluye en momentos anteriores, es decir, no puede ser anterior a la presencia fenicia en Occidente, y se insiste en que los materiales que hasta el momento servían para definir el período local previo no podrán ser así utilizados nunca más (Fernández y Rodríguez, 2005a: 136) ${ }^{19}$.

Una primera monografía y por ello mucho más elaborada, aparecerá dos años después, en la que se describen los trabajos realizados y se hace una primera interpretación que podríamos denominar global (Fernández y Rodríguez, 2007). En relación con la ocupación previa al santuario, nos interesa aquí como una reiteración de la nueva concepción que se quiere dar al Carambolo, cuando se dice ... que la cronología e interpretación del Carambolo Alto carecen de fundamento [...] ni la datación dada a los restos recuperados [...] ni su lectura como fondo de cabaña se puede mantener a la luz de las últimas intervenciones arqueológicas (Fernández y Rodríguez, 2007: 246), espe-

18 Ahora se amplía la fase final de esta primera fase hasta el Bronce Medio acortando el hiato.

19 En cita a pie de página (8) se menciona la posibilidad de que existiera una antigua ocupación del Bronce precolonial, pero que tal vez fue destruida en trabajos de ampliación para la construcción del santuario, ya que donde se ha podido observar solo aparecen sedimentos de vertido. cialmente porque el santuario fenicio ...se asienta sobre un enclave, al parecer deshabitado desde los últimos momentos del Broce Tardio o Medio, donde el $<<$ fondo de cabaña $>>$ documentado por Carriazo aparece como un simple depósito de relleno dentro de una gran fosa de carácter ritual, en la que se acumularon los restos sacrificales y cultuales que presenta una cronología claramente colonial desde su nivel inferior (Fernández y Rodríguez, 2007: 246). Sin embargo, en páginas anteriores se reconocía que se habían documentado fosas con restos de sacrificios en una de las zonas excavadas, donde ...los niveles detectados correspondientes al supuesto $<<$ fondo de cabaña > excavado por J. M. Carriazo no son más que algunos de los depósitos contenidos en una de estas fosas, que a su vez corta a una fosa previa (Fernández y Rodríguez, 2007: 231-232), un importante indicador estratigráfico sobre el que volveremos ${ }^{20}$.

Un nuevo trabajo publicado explicará también de forma global las excavaciones, ahora más matizada al haber estudiado por primera vez materiales pertenecientes a algunos de los contextos (Fernández y Rodríguez, 2010). Otra vez se reitera la nueva interpretación del Carambolo que invalidaba la tesis tartésica mantenida a lo largo de la segunda mitad del siglo XX, a pesar de que ahora aparecerán nuevos datos que deberían haberse tenido en cuenta. Se parte de que ...las relacione estratigráficas de la fosa-basurero, la cronología aportada por los materiales cerámicos recuperados en la misma y las fechas obtenidas por C14, ofrecen una datación claramente colonial para todos los estratos e incluso para la propia interfacie, por lo que el repertorio material que sirvió para definir una cultura tartésica previa a la colonización quedó sin fundamento científico, siendo necesaria una nueva caracterización arqueológica de las "posibles" poblaciones precoloniales (Fernández y Rodríguez, 2010: 204). Sin embargo, más adelante, se menciona que la ocupación del sitio comienza con dos horizontes calcolíticos, quizás pre y campaniforme, formado por fosas, hogueras y un enterramiento, pero no se descarta aquí la existencia de cabañas, y también de fosas.

20 La existencia de dos fosas superpuestas (¿cabañas/ pithouses/basureros?) es muy importante para entender la verdadera estratigrafía del Carambolo Alto, una circunstancia que tal vez no pudo observarse en 1958 y que ahora no se ha tenido en cuenta. 
El segundo período, que es el que aquí nos interesa especialmente, comprenderá ahora un Bronce Tardío-Final, que fecharán 1400-1100 A.C. a partir del análisis radiométrico practicado ... al contenido de una de las fosas que en origen se atribuían al periodo Calcolítico (Fernández y Rodríguez, 2010: 214). Este inesperado horizonte ahora mencionado por primera vez se localiza en el noroeste del cerro, ...en el interior de una gran fosa de planta circular (1210), con un diámetro aproximado de $2,50 \mathrm{~m}$, que muestra en su interior una complicada secuencia de fosas y deposiciones (Fernández y Rodríguez, 2010: 214), que se identifica como posible silo o basurero, y también se estima su posible uso ritual. La datación radiocarbónica más probable se sitúa entre 1401 A.C. y 1131 A.C. y los materiales arqueológicos son relacionados con el Llanete de los Moros IIIa y IIIb, y el Castillo de Monturque, pero también con Umbría II, aunque asimismo se mencionan el Cabezo de San Pedro (Fase I), Setefilla (Fase IIa) y Colina de los Quemados (estratos 18 a 16), los cuales no cuentan con otras dataciones que las arqueológicas del siglo pasado (Fernández y Rodríguez, 2010: 215-216)21, y tal vez por ello no se paralelizan en su adscripción al Bronce Final. El tercer período de ocupación corresponde al santuario desde el siglo IX a.C. y su evolución continuada a través del tiempo.

Nos parece interesante resaltar que, en las conclusiones de este artículo, donde se contemplan tanto los nuevos datos del Carambolo como gran parte del repertorio protohistórico del Suroeste, explícitamente se puntualiza que los datos ...no conllevan el afirmar que exista un vacio poblacional en el periodo citado en el suroeste andaluz, sólo intentamos poner de manifiesto que, con los datos disponibles en este momento, no podemos realizar una caracterización arqueológica fundamentada de las poblaciones residentes en este territorio en el periodo indicado, ni siquiera afirmar la presencia ...[sic.]... de las mismas (Fernández y Rodríguez, 2010: 261).

En primer lugar, después de estas afirmaciones el pretendido vacío poblacional del Suroeste ha desaparecido para siempre, incluso en la antigua desembocadura del Guadalquivir, y segundo, que el

21 Los cinco fragmentos presentados en la figura 11, tal vez bruñidos, y su cronología del II Milenio dentro del Bronce Final derriban como un castillo de naipes todas las interpretaciones anteriores. hecho de que los autores no puedan confirmar la existencia de población continuada anterior se debe a problemas propios, relacionados seguramente con la inercia de los años anteriores y no al carácter científico que debe prevalecer en todo proceso de investigación, pues los nuevos datos imponían una corrección a las manifestaciones anteriores.

Nosotros creemos que el principal problema de la explicación de El Carambolo que se había hecho a partir de su excavación ha sido confundir una estructura de tipo pithouse, ${ }^{22}$ como la cabaña excavada por J. M. Carriazo y ahora otras estructuras ${ }^{23}$, con una de tantas fosas de vertido que de costumbre aparecen en ciudades medievales y contemporáneas como Sevilla, ambas rellenas de basura. En los dos tipos de estructuras, unidades negativas excavadas en el subsuelo, el relleno -positivo- será siempre posdeposicional en el primero de los casos e invariablemente estará formado por depósitos de génesis natural y también antropizada y, por ello, tendrán que ser sincrónicos a la destrucción o amortización de la cabaña semisubterránea ocupada, sobre la que además se depositará un relleno posterior a su destrucción $^{24}$ que colmataría el hueco resultante; el segundo caso son solo rellenos antrópicos heterogéneos como vulgar basurero, que pueden o no estar estratificados si los vertidos se hicieron en momentos sucesivos.

22 Para una teórica descripción de las cabañas tipo pithouse o dwelling-pits ver V. Jiménez Jáimez (2007), con bibliografía; para cabañas semisubterráneas europeas ver Sabjan (2003) entre otros. Lo principal es que no se trata de una vivienda más atrasada con respecto a las construidas con muros de piedra por encima de la rasante y planta regular, sino una estructura más factible en zonas donde la piedra sea difícil de conseguir, como en el entorno del Carambolo. Desde el punto de vista de la interpretación arqueológica de sus rellenos, entendiendo así nuestros 'fondos de cabaña', se eliminan muchos de los problemas que esas estructuras han planteado hasta ahora (Gómez y otros, 2009).

23 A pesar de la exigua descripción con que contamos de las estructuras negativas documentadas y explicadas en general como fosas de vertido (Fernández y Rodríguez, 2010: 215 y ss), las adscritas tanto al Bronce Tardío-Final (1400-1100 A.C.) como otras protohistóricas posteriores (1020-810 A.C.), además de indicar continuidad poblacional desde el II Milenio a.C., son sin duda ejemplos a estudiar desde el concepto de pithose o dwelling-pit.

24 Por esta morfología postdeposicional, los ejemplos excavados por la geografía del Suroeste nunca presentan una estructura regular, toda vez que, si la cabaña se ha destruido para erigir una nueva, los elementos estructurales, tales como postes y partes vegetales en buen estado, se reutilizan en la erección de una nueva, o para hacerlas leña, con lo que se diluyen aquellos indicios esperados para confirmar su función de vivienda. 


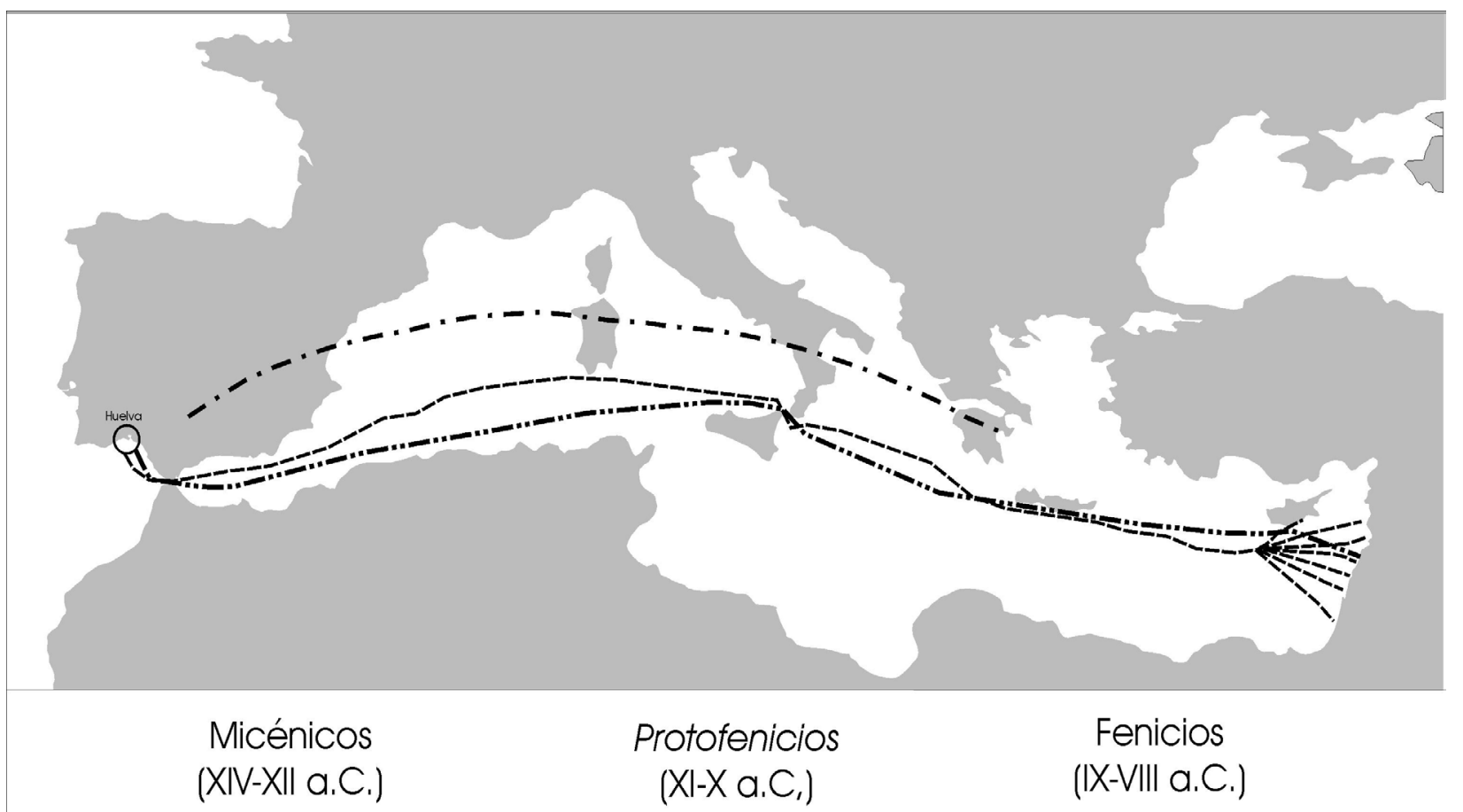

Figura 3.- Fases de contacto entre el Mediterráneo Oriental y la Península Ibérica.

En las últimas décadas se ha debatido demasiado de la existencia o no de materiales orientales en el fondo de cabaña, pero nunca se ha dicho en qué zona habrían aparecido los aparentemente excavados en esos años. En primer lugar, el torno está documentado en el Suroeste desde el hallazgo de Montoro (Martín de la Cruz, 2008); en segundo lugar, la excavación realizada en 1958 no pudo tener la pulcritud que ahora se exige; finalmente, hemos de reiterar que si se trataba de una pithouse como parece evidente, los rellenos siempre serán postdeposicionales, es decir, posteriores a la amortización de esa cabaña y de los materiales que se utilizaron en su momento de ocupación, lo cual posibilitaría la presencia de elementos a torno siempre posteriores al momento en que la cabaña estuvo en uso, y nunca significará que fuese coetánea de la presencia del torno; lo importante es delimitar entre sedimentos previos debidos a su ocupación, si es que existen, y rellenos posteriores resultantes de su abandono o amortización.

En relación con la interpretación de la evolución posterior del sitio en particular, como hipótesis a contrastar en el futuro, posiblemente se trate de un santuario de tipo oriental ${ }^{25}$ generado a partir de un

25 Nos parece acertada la atribución oriental, no fenicia o lugar sagrado o cultual de la Edad del Bronce que, como tantos otros aspectos de la superestructura local previa, fue orientalizado después de varios siglos durante los que se habían mantenido contactos con gentes del círculo próximo-oriental mediterráneo (Figura 3). La cabaña del tipo pithouse excavada por J. M. Carriazo (1973), muy bien interpretada estructuralmente en su día por J. Maluquer $(1994)^{26}$, teniendo en cuenta el lugar que ocupaba, pudo ser uno de los precedentes del santuario orientalizante posterior, tal como en alguna ocasión se había interpretado (Belén y Escacena, 1997), y como ya habían intuido Carriazo y A. Blanco (1979).

cananeo-fenicia, del santuario del Carambolo que a veces hace A. Gómez Peña (2010), en especial por la cronología amplia que cita en relación con el origen de los ox-hide ingots en un mundo oriental que denomina asirio-chipriota. Precisamente el vacío temporal en el mundo mediterráneo desde el final de la Edad del Bronce y la aparición en la Península Ibérica de los altares de piel de buey en un momento del Período Orientalizante nos debería hacer pensar que nos situamos claramente en la disyuntiva que llevó a S. Moscati (1988: 24) a mencionar cómo tantas ambigüedades y teorías presupuestas planeaban libremente sobre la explicación de la Protohistoria mediterránea.

26 El más importante indicador sería la presencia de pellas de barro endurecidas en un incendio y con impronta de cañas o ramas, que al haber formado parte de la cubierta vegetal no pueden ser basuras de sacrificios o comidas rituales. 
El tamaño de la estructura ahora excavada, si se trata de la primera cabaña y no de la que se le superpone (Fernández y Rodríguez, 2007: 149), sería un buen ejemplo para relacionarla con unos rituales locales que en parte desconocemos (Tejera y Fernández, 2012). En el Bronce Final, el paso de deidades locales a otras ya vinculadas claramente con el mundo mediterráneo nos parece una situación lógica, si pensamos tanto en Reshef como en el Hércules gaditano tal como se desprende de la lastra del museo de Ostia (Corzo, 2005: fig. 16A), donde se representan a esos dioses mediterráneos con la iconografía que los caracterizará a través del tiempo, tal como el lingote de piel de buey grabado sobre la cista de Melkhart o Reshef, de la cual el Hércules gaditano extrae una tablilla, y además su gesto amenazante. ¿Es este ejemplo un recuerdo de los altares orientalizantes o quizá el símbolo de un dios oriental de la Edad del Bronce con uno de los atributo de un smiting god como el dios cornudo de Enkomi ${ }^{27}$ ?

\section{COMO CONCLUSIÓN ¿UN NUEVO PUNTO DE PARTIDA?}

En relación con la probada existencia del período que denominamos Bronce Final prefenicio en el Suroeste, reconocida la antigua presencia de orientales heterogéneos en Occidente como punto crucial del debate, y a quiénes debemos considerar fenicios, somos conscientes que cualquier postura extrema será criticable por una u otra línea de investigación. Para los elementos más antiguos del conjunto publicado de Huelva, que aporta una clara novedad digna de tenerse en cuenta, una interpretación lógica razonada es que ...the earliest defendible date for some of Phoenician pieces at Huelva is indeed somewhere around Ir2a. This would mean the tenth century according to conventional Palestine ceramic chronology, or the entire 980-830 range following Mazar's 'extended high chronology' and solely the ninth century by the low chronology we advocate (Gilboa y otros, 2009: 172). Es decir, al menos existen tres posibles dataciones que pueden satisfacer a los diferentes investigadores para que el debate se prolongue.

Pero, incluso por su datación lógica, y de acuerdo a cómo se manifiesta el proceso histórico en el Próximo Oriente que ahora coloca a los fenicios

27 Debe tenerse en cuenta que el lingote de piel de buey no es una imagen fenicia, pues desaparece del registro mediterráneo a partir de la crisis del 1200 a.C. (Lo Schiavo y otros, 2009). históricos en un espacio temporal específico, esas cerámicas fenicias previas a mediados del siglo IX a.C. también pudieron llegar en barcos orientales - protofenicios- ya que ...the evidence of Phoenician presence, if not necessarily representing colonisation - are only of later types, not earlier than the eighth century BCE (Gilboa y otros, 2009: 191), es decir en sincronía con el $M G$ ático, del cual existen bastantes ejemplos localizados en el mismo contexto onubense y también en El Carambolo.

Resulta claro pues, que el puerto de Huelva existía en momentos previos a la presencia fenicia, como se demostró en el Cabezo de San Pedro hace más de cuarenta años (Blázquez y otros, 1970), y ahora en su ruedo agrícola (Beltrán y otros, e.p.), que indica la necesaria convivencia en el lugar de la sociedad de la Edad del Bronce y la presencia de otros agentes comerciales en momentos previos a esos fenicios históricos.

Pero de lo que ya no hay duda, de acuerdo con los propios autores, es que en El Carambolo se ha excavado, y así debe interpretarse, un hábitat de cabañas que muestra la continua evolución de la Prehistoria reciente desde la segunda mitad del II Milenio a.C., con un inicio que podríamos relacionar con nuestro Horizonte Formativo del Bronce Final de Huelva (Gómez, 2008).

Que ese Horizonte continuaría con su propia evolución local durante el Horizonte Clásico del Bronce Final y, en su fase más tardía y algo antes de la presencia fenicia, continuaría el registro publicado en su día por J. M. Carriazo (1973) con el ajuar del fondo de cabaña-pithouse del Carambolo Alto, según mostrarán los materiales asociados a tantas fosas de vertido-pithouses- como mencionan los autores de su reciente excavación, de hecho pertenecientes a un poblado de cabañas relativamente extenso.

En un momento final de este Horizonte Clásico, se asistirá a la presencia definitiva de los fenicios históricos y por ello, a partir de allí, a la orientalización generalizada del Suroeste, incluyendo claro está la fase que le corresponda al santuario, bien sea pre-fenicia o bien sea relacionable con los que aquí denominamos fenicios históricos, por supuesto posteriores a Hiram I. En esa fase local, las cabañas muestran materiales de importación, con ejemplos, además de los fenicios, de vasos del Geométrico griego y del Mediterráneo central en general, se- 
gún se desprende del contenido de las cabañas de ese momento (Escacena y otros, 2007) ${ }^{28}$.

Finalmente, según interpretamos en la Figura 3, cualquier elemento oriental previo al siglo IX a.C. localizado en la Península Ibérica no debe ser considerado fenicio, toda vez que se cuenta con suficientes datos contrastados desde el II Milenio a.C. para estimarlo así. Hace falta puntualizar o acuñar una descripción que sea coherente con el nuevo conocimiento fundamentado en el registro arqueológico.

\section{BIBLIOGRAFÍA}

Albright, W. F. (1954), The Archeology of Palestine (Ed. Rev.), Harmondsworth.

Almagro Basch, M. (1981), "La interpretación de la leyenda de Tartessos según los documentos arqueológicos", Revista de la Universidad Complutense, 1, 54-73.

Almagro Gorbea, M. (1977), El Bronce Final y el Periodo Orientalizante en Extremadura, Bibliotheca Praehistorica Hispana, XIV, Madrid.

Alvar, J. (2008), "Modos de contacto y medios de comunicación, los orígenes de la expansión fenicia”, Contacto cultural entre el Mediterráneo y el Atlántico (siglos XII-VIII ane). La precolonización a debate (S. Celestino, N. Rafel, y X.L. Armada, Eds.), Serie Arqueológica, II, Madrid, 19-25.

Antonelli, L. (2006), “Da Tarsis a Tartesso. Riflessioni sulla presenza greca oltre Gibilterra durante l'età arcaica", Gerión, 24/1, 7-26.

Aubet Semmler, $\mathrm{M}^{\mathrm{a}}$.E. (1987), Tiro y las colonias fenicias en Occidente, Bellaterra, Barcelona.

(2003), "El comercio fenicio en Homero", Estudios de Arqueología dedicados a la profesora Ana María Muñoz Amilibia (S.M. Ramallo, Ed.), 85-101.

(2006), "El sistema colonial fenicio y sus pautas de organización”, Mainake, XXVIII, 35-47.

(2008), "Political and economic implications of the new Phoenician chronologies", Beyond the Homeland. Markers in Phoenician Chronology (C. Sagona, Ed.), Ancient Near Eastern Studies, Suppl, 28, Lovaina, 247-259.

(2009), "Byblos y Tiro. Desarrollo y reestructuración urbanísticas en Fenicia", Phönizisches

28 En relación con la posible maqueta de barco publicada, considerada un híppos fenicio (Escacena y otros, 2007), según se observa a simple vista, la pasta en que se fabricó indica ser una fabricación sarda. und punisches Städtwesen (S. Helas y D. Marzoli, Ed.), Iberia Archaeologica, 13, Mainz, 2137.

Bauer, A. A. (1998), "Cities of the Sea, Maritime Trade and the Origin of Philistine Settlement in the Early Iron Age Southern Levant”, Oxford Journal of Archaeology, 17/2, 19-168.

Belén, Ma . y Escacena, J.L. (1997), “Testimonios religiosos de la presencia fenicia en Andalucía Occidental", Spal, 6, 103-131.

Beltrán, J.M., Gómez, F., Vera, J.C. y González, D. (en prensa), "Secuencia estratigráfica de un conjunto de fondos de cabaña del Bronce del yacimiento La Orden-Seminario (Huelva)", Huelva Milenaria, Homenaje a Javier Rastrojo Lunar, Universidad de Huelva.

Bikai, P.M. (1978), The pottery of Tyre, Warminster.

(1989), "The Phoenicians", The Crisis Years, The $12^{\text {th }}$ Century B.C.From Beyond the Danube to the Tigris (W.A. Ward y M.S. Joukowsky, Eds.), Dubuque, 132-141.

Blanco, A. (1956), "Orientalia, Estudio de objetos fenicios y orientalizantes en la Península", $A r$ chivo Español de Arqueología, 29, 3-51.

(1960), “Orientalia II”, Archivo Español de Arqueología, 33, 3-43.

(1979), Historia de Sevilla, I (1). La ciudad antigua (De la Prehistoria a los Visigodos), Universidad de Sevilla.

Blázquez, J.Ma . (2005), "Evolución del concepto orientalizante en los últimos 50 años en la investigación hispana”, El período orientalizante. Protohistoria del Mediterráneo Occidental (S. Celestino y J. Jiménez, Eds.), Anejos de Archivo Español de Arqueología 35, Madrid, 129148.

Blázquez, J.Mํㅗ., Luzón, J.Mํa ., Gómez, F., y Clauss, K. (1970), Huelva Arqueológica. Las cerámicas del Cabezo de San Pedro, Huelva.

Bodine, J.J. (2010), "Gates, Dates, and Debates. A Review of Megiddo's Monumental Gate and the Debates over Archaeology and Chronology in Iron Age Palestine”, Studia Antiqua, 8/1, 5-23.

Brandherm, D. (2008), "Vasos a debate, La cronología del Geométrico Griego y las primeras colonizaciones en Occidente", Contacto cultural entre el Mediterráneo y el Atlántico (siglos XII-VIII ane). La precolonización a debate (S. Celestino, N. Rafel y X.L. Armada, Eds,), Serie 
Arqueológica II, Madrid, 93-106.

Bruins, H.J. Nijboer, A.J. y Plicht, J. van der (2011), "Iron Age Mediterranean Chronology. A Reply”, Radiocarbon, 53/1, 199-220.

Carpenter, R. (1958), "Phoenicians in the West", American Journal of Archaeology, 62/1, 3553.

Carrasco, J.A. y Pachón, J.A. (2006), "Sobre la cronología de las Fíbulas de Codo tipo Huelva”, Archivo de Prehistoria Levantina, XXVI, 245291.

Carriazo, J. de M. (1973), Tartesos y El Carambolo, Madrid.

(1980), Protohistoria de Sevilla. En el vértice de Tartesos, Sevilla.

Celestino, S., Rafel, N. y Armada, X.L., -Eds.(2008), Contacto cultural entre el Mediterráneo y el Atlántico (siglos XII-VIII ane), La precolonización a debate, Serie Arqueológica, II, Madrid.

Corzo, R. (2005), "Sobre las primera imágenes y la personalidad originaria de Hercules Gaditanus", Spal, 14, 91-122.

Culican, W. (1966), The First Merchant Venturers, The Ancient Levant in History and Commerce, London.

De La Bandera, M ${ }^{\mathrm{a}}$.L. y Ferrer, E. (2010), El Carambolo, 50 años de un tesoro, Sevilla.

Dever, W.G. (1989), "The Late Bronze-Iron I Horizon in Syria-Palestine, Egiptians, Canaanites, 'Sea Peoples', and Proto-Israelites", The Crisis Years, The $12^{\text {th }}$ Century B.C. From Beyond the Danube to the Tigris (W.A. Ward y M.S. Joukowsky, Eds.), Dubuque, 99-110.

Dongen, E. van (2010), "Phoenicia. Naming and Defining a Region in Syria-Palestine", Interkulturalität in der Alten Welt Vorderasien, Hellas, Ägypten und die vielfältigen Ebenen des Kontakts (R. Rollinger, B. Gufler, M. Lang e I. Madreiter, Eds,), Wiesbaden, 471-488.

Escacena, J.L.(2008), "Cantos de sirena. la Precolonización Fenicia de Tartessos", Contacto cultural entre el Mediterráneo y el Atlántico (siglos XII-VIII a.n.e.). La precolonización a debate (S. Celestino, N. Rafel, y X.L. Armada, Eds,), Serie Arqueológica, II, Madrid, 301-322.

(2005), "El Templo y la Ciudad, Que trata de cómo los fenicios poblaron Sevilla y su entorno", $\mathrm{Ca}$ tedral de Sevilla, Avla Hernan Rviz, 1-21.

Escacena, J.L., Fernández, A. y Rodríguez, A. (2007), "Sobre El Carambolo. Un Hippos sagra- do del santuario y su contexto arqueológico”, Archivo Español de Arqueología, 80, 5-28.

Fantalkin, A., Finkelstein, I. y Piasetzky, E. (2011), "Iron Age Mediterranean Chronology, A Rejoinder”, Radiocarbon, 53/1, 179-198.

Faust, A. y Lev-Tov, J. (2011), “The Constitution of Philistine Identity. Ethnic Dynamics in Twelfth to Tenth Century Philistia", Oxford Journal of Archaeology, 30/1, 13-31.

Feinman, P.D. (2004), William Foxwell Albright and the Origins of Biblical Archaeology, Andrews University Press, Berrien Springs.

Fernández, A, y Rodríguez, A, (2005a), "El complejo monumental del Carambolo Alto, Camas (Sevilla). Un santuario orientalizante en la paleodesembocadura del Guadalquivir", Trabajos de Prehistoria, 62/1, 111-138.

(2005b), "Nuevas excavaciones en el Carambolo Alto, Camas (Sevilla). Resultados preliminares", El Periodo Orientalizante en la Península Ibérica (S. Celestino y J. Jiménez, Ed.), Anejos de Archivo Español de Arqueología, XXXV, Madrid, 843-861.

(2007), Tartessos desvelado, La colonización fenicia del Suroeste peninsular y el origen y ocaso de Tartessos, Almuzara, Córdoba.

(2010), "El Carambolo, secuencia cronocultural del yacimiento. Síntesis de las intervenciones 20022005”, El Carambolo, 50 años de un tesoro $\left(\mathrm{M}^{\mathrm{a}}\right.$.L. de la Bandera y E. Ferrer, Coords.), Sevilla, 203-270.

Finkelstein, I. (1996), "The Archaeology of the United Monarchy. An alternative view”, Levant, XXVIII, 177-187.

(1998), "Bible Archaeology or Archaeology of Palestine in the Iron Age? A Rejoinder", Levant, XXX, 167-74.

(2000), "Omride Architecture", Zeitschrift des Deutschen Palästina-Vereins, 116,114-138.

(2001), "The Rise of Jerusalem and Judah, the Missing Link", Levant, 22, 105-115.

(2006), "The Iron I-IIA in the Highlands and Beyond:14C Anchors, Pottery Phases and The Shoshenq I Campaign", Levant, 38, 45-61

(2007), "Is the Philistine Paradigm still viable?", Contributions to the Chronology of the Eastern Mediterranean. The Synchronisation of Civilizations in the Eastern Mediterranean in the Second Millennium B.C.(M. Bietak y E. Czerny, Ed.), Viena, 517-523. 
(2008), "Una Actualización de la Cronología Baja. Arqueología, Historia y Biblia”, Antiguo Oriente, 6, 115-136.

(2010), "A Great United Monarchy? Archaeological and Historical Perspectives", One God-One Cult- One Nation (R.G. Knatz y H. Spieckermann, Ed.), Archaeological and Biblical Perspectives, Beihefte zur Zeitschrift für die alttestamentliche Wissenschaft, 405, Berlin, 3-28.

(2011a), "Stages in the Territorial Expansion of the Northern Kingdom”, Vetus Testamentum, 61, 227-242.

(2011b), "Observations on the Layout of Iron Age Samaria”, Tel Aviv, 38, 194-207,

(2012), "The Great Wall of Tell en-Nasbeh (Mizpah). The First Fortifications in Judah, and 1 Kings 15:16-22”, Vetus Testamentum, 62, 1428.

Finkelstein, I. y Piasetzky, E. (2007), "Radiocarbon Dating and Philistine Chronology", Egypt and the Levant (M. Bietak, Ed.), Viena, 73-82.

(2009), "Radiocarbon Dating Destruction Layers: A Skeleton for Iron Age Chronology in the Levant", Oxford Journal of Archaeology, 28/3, 255-274.

Finkelstein, I. y Lipschits, O. (2010), "Omride Architecture in Moab, Jahaz and Ataroth", Zeistschrift des Deutschen Palästina-Vereins, 126/1, 29-42.

Finkelstein, I. y Silberman, E. (2001), The Bible Unearthed. Archaeology's New Vision of Ancient Israel and the Origin of Its Sacred Texts, Nueva York.

(2003), La Biblia desenterrada. Una nueva visión arqueológica del antiguo Israel y de los orígenes de sus textos sagrados, Trad. Esp. de The Bible Uneartherd, Madrid.

Fleming, W.B. (1915), The History of Tyre, Columbia University Oriental Studies, X, Lancaster/New York.

Frutos, G. de (1991), Cartago y la politica colonial, Los casos norteafricano e hispano, Sevilla.

Ganor, N.R. (2009), Who were the Phoenicians?, Kotarinm International Publishing Ltd, Eisenbrauns, Winona Lake.

García y Bellido, A. (1960), "Inventario de los jarros púnico-tartésicos”, Archivo Español de Arqueología, 33, 44-63,

García, L. y Hurtado, V. (2011), "Las dataciones radiocarbónicas de El Trastejón en el marco de la cronología absoluta de la Edad del Bronce (c. 2200-850 A.N.E.) en el Sur de la Península Ibérica”, El asentamiento de El Trastejón (Huelva). Investigaciones en el marco de los procesos sociales y culturales de la Edad del Bronce en el Suroeste de la Península Ibérica (V. Hurtado, L. García y M. A. Hunt, Coords.), Sevilla, 138-160.

Gilboa, A., Sharon, I. y Boaretto, E. (2009), “Tel Dor and the chronology of Phoenician "precolonization" stages, Beyond the Homeland, Markers in Phoenician Chronology (C. Sagona, Ed.), Monograph Series of Ancient Near Eastern Studies, Lovaina, 113-204,

Gitin, S., Mazar, A. y Stern, E. (1998), Mediterranean Peoples in transition. Thirteenth to Early Tenth Century BCE, Jerusalén.

Gómez Peña, A. (2010), “Así en Oriente como en Occidente. El Origen Oriental de los Altares taurodérmicos de la Península ibérica”, Spal, 19, 128-148.

Gómez, F. (1997), Formas de ocupación del territorio durante los primeros siglos del I Milenio a.C., El Suroeste como marco de definición y contrastación, Tesis Doctoral, Edición Electrónica, 15, Servicio de Publicaciones de la Universidad de Huelva, Huelva, 1-577.

(2004), "Cerámicas Fenicias en el Suroeste Atlántico Andaluz, Una reflexión crítica”, Mirando al Mar, Perspectivas desde el Poniente Mediterráneo, II y I Milenios A.C. Revista de Prehistoria, 3, 63-114.

(2008), "Cerámicas del Bronce Final en Huelva (1200-600 a.C.). Nueva tipología para explicar su amplitud cronológica", Homenaje a Pilar Acosta, Tabona, 16, 85-100,

(2009), "Huelva en el año 1000 a.C., un puerto cosmopolita entre el Atlántico y el Mediterráneo", Gerión, 27/1, 33-65.

(en prensa), "El mundo mediterráneo y Tarteso a la luz de nuevas evidencias", Actas I Congreso Internacional Tarteso el emporio del metal, Universidad de Huelva.

Gómez, F. y Fundoni, G. (2011), "Relaciones del Suroeste con el Mediterráneo en el Bronce Final (siglos XI-X a.C.). Huelva y la isla de Cerdeña”, Anales de Arqueología Cordobesa, 21/22, 17-56.

Gómez, F., Linares, J.A. y De Haro, J. (2009), "Fondos de cabaña del Bronce Final-Orientali- 
zante en la Tierra Llana de Huelva”, Actas IV Encuentro de Arqueología del Suroeste Peninsular, Huelva, 606-647.

González, F., Serrano, L., y Llompart, J. (2004), El Emporio Fenicio Precolonial de Huelva (ca. 900-770 a.C.), Madrid.

(2006), "The pre-colonial Phoenician emporium of Huelva ca. 900 - 700 B.C." Bulletin Antieke Beschaving, 81, 13-29.

(2008), "The emporium of Huelva and Phoenician chronology, present and future possibilities", Beyond the Homeland, Markers in Phoenician Chronology (C. Sagona, Ed.), Monograph Series of Ancient Near Eastern Studies, Lovaina, 631-655.

(2010), "El inicio de la Edad del Hierro en el Suroeste de la Península Ibérica, las navegaciones precoloniales, y cuestiones en torno a las cerámicas locales de Huelva”, IV Encuentro de Arqueología del Suroeste, Huelva, 648-698.

Harden, D. (1963), Los Fenicios, Barcelona.

Herrera, Mํ.D. y Gómez, F. (2004), Tell Abu Hawam (Haifa, Israel), El Horizonte fenicio del Stratum III Británico, Huelva.

Jiménez, J. y Guerra, S. (2012), "El Bronce Final en Medellín. Estudio preliminar del Corte SMRO”, Sidereum Ana II, El río Guadiana en el Bronce Final (J. Jiménez Ávila, Ed.), Anejos de Archivo Español de Arqueología, LXII, 65110.

Jiménez, V. (2007), "Pithouses versus pits. Apuntes para la resolución de un problema arqueológico”, Portugalia, Nova Série, XXVIIXXVIII, 35-48.

Joffe, A. H. (2002), "The rise of Secondary States in the Iron Age Levant”, JESHO 45/4, 426-467.

Katzenstein, H.J. (1973), The History of Tyre. From the Beginning of the Second Millennium B,C,E, until the Fall of the Neo-Babylonian Empire in 538 B.C.E., Jerusalén.

Lehmann, G. (1998), “Trends in the Local Pottery Development of the Late Iron Age and Persian Period in Syria and Lebanon, ca. 700 to 300 B.C.”, Bulletin of the American Shools of Oriental Research, 311, 7-37.

Lo Schiavo, F., Muhly, J. D., Madding, R. y Giumlia-Mair, A. (2009), Oxhide Ingots in the Central Mediterranean, Instituto di Studi sulle Civiltà dell'Egeo e del Vicino Oriente, Roma.

Maluquer de Motes, J. (1968), Tartessos. La ciudad sin historia, Barcelona.
(1994), Excavaciones de El Carambolo, Sevilla. Notas y experiencias personales 1958, Ed. Facsímil, Clásicos de la Arqueología de Huelva, 5, Huelva.

Martín de la Cruz, J.C. (2008), "El Valle Medio del Guadalquivir", Contacto cultural entre el Mediterráneo y el Atlántico (siglos XII-VIII ane), La precolonización a debate (S. Celestino, N. Rafel, y X.L. Armada, Eds,), Serie Arqueológica, II, Madrid, 289-299.

Mazar, A. (2005), "The Debate over the Chronology of the Iron Age in the Southern Levant. Its history, the current situation, and a suggested resolution", The Bible and Radiocarbon Dating, Archaeology, Text and Science (T.E. Levy y T. Higham, Ed.), London, 15-30.

(2010), "Archaeology and the Biblical Narrative: The Case of the United Monarchy", One GodOne Cult-One Nation, Archaeological and Biblical Perspectives (R. G. Kratz y H. Spiekermann, Ed.), Beihefte zur Zeitschrift für die alttestamentliche Wissenschaft, 405, Berlín, 29-58.

(2011), "The Iron Age chronology debate, is the gap narrowing? Another viewpoint", Near Eastern Archaeology, 74, 105-110.

Mederos, A. (2004), "Fenicios evanescentes, Nacimiento, muerte y redescubrimiento de los fenicios en la península Ibérica, II (1936-1968)”, Saguntum, 36, 35-46.

Moscati, S. (1983), "Precolonizzazione greca e precolonizaciones fenicia”, Revista di Studi Fenici, 11/1, 1-7.

(1988), "Chi furono I Fenici", I Fenici (S. Moscati, Dr.), Milán, 24-25.

Movers, F.E. (1841), Die Phonizier I, Bonn.

Na'Aman, N. (1986), "Habiru and Hebrews. The Transfer of a Social Term to the Literary Sphere", Journal of Near Easter Studies, 45/4, 271-288.

Nijboer, A.J. y van der Plicht, J. (2006), "An interpretation of the radiocarbon determinations of the oldest indigenous- Phoenician stratum thus far, excavated at Huelva, Tartessos (south-west Spain)”, Bulletin Antieke Beschaving, 81, 4146.

Pulak, C. (1998), “The Uluburun shipwreck, an overview", The International Journal of Nautical Archaeology, 27/3, 188-224.

Plicht, J. van der, Bruins, H.J. y Nijboer, A.J. (2009), "The Iron Age around the Mediterra- 
nean: A High Chronology Perspective from the Groningen Radiocarbon Database”, Radiocarbon, 51/1, 213-242.

Rawlinson, G. (1889), History of Phoenicia, Oxford.

Röllig, W. (1983), "On the Origin of the Phoenicians", Berytus, 31, 79-93.

(1995), "Phoenician and the Phoenicians in the Context of the Ancient Near East", I Fenici, ieri, oggi, domani, Accademia Nazionale dei Lincei, Commissione per gli studi Fenici e Punici, Roma, 203-214.

Rowlands, M.J. (1980), "Kinship, alliance and exchange in the European Bronze Age", Settlement and Society in the British Later Bronze Age (J. Barret \& R. Bradley, Eds.), B.A.R. 83, Oxford, 15- 55.

Ruiz Mata, D. y Gómez, F. (2008), "El final de la Edad del Bronce en el Suroeste Ibérico y los inicios de la colonización fenicia en Occidente", Contacto cultural entre el Mediterráneo y el Atlántico (siglos XII-VIII ane). La precolonización a debate (S. Celestino, N. Rafel, y X.L. Armada, Eds.), Serie Arqueológica, II Madrid, 323-353.

Sabján, T. (2003), "Reconstruction of Medieval pit-houses”, Památky Archeologické, Ruralia, IV, Supplementum, 15320-332,

Sherrat, S. (1998), "Sea Peoples" and the Economic Structure of the Late Second Millenium in the Eastern Mediterranean”, Mediterranean Peoples in Transition, Thirteenth to Early Tenth Centuries BCE (S. Giti, A. Mazar y E. Stern, Eds.), Jerusalén, 292-313.

Stieglitz, R.R. (1990), "The Geopolitics of the Phoenician Littoral in the Early Iron Age", Bulletin of the American Schools of Oriental Research, 279, 9-12.

Stampolidis, N. C. (2003), "A summary glance at the Mediterranean in the early Iron Age $\left(11^{\text {th }}-6^{\text {th }}\right.$ c, BC)", Sea Routes...From Sidon to Huelva. Interconnectios in the Mediterranean 16th6th c. $B C$ (N. Chr. Stampolidis, Ed.), Atenas, 41-79.

Tarradell, M. (1963), "Los fenicios en Occidente. Nuevas perspectivas", Los Fenicios (D. Harden), Barcelona, 277-314.

Tejera, A. y Fernández, J. (2012), Los dioses de los tartesios, Bellaterra-Arqueología, Barcelona.

Torres, M. (2008), "Los «tiempos» de la Precolonización”, Contacto cultural entre el Medite- rráneo y el Atlántico (siglos XII-VIII ane). La Precolonización a debate (S. Celestino, N. Rafel y X.L. Armada, Eds), Madrid, 59-106.

(2012), "La Precolonización en Extremadura", Sidereum Ana II.El río Guadiana en el Bronce Final (J. Jiménez Ávila, Ed.), Anejos de Archivo Español de Arqueología, LXII, 455-474.

Vilaça, R. (2006), “Artefactos de ferro em contextos do Bronze Final do Território portugués: Novos contributos e reavaliação dos dados", Complutum, 17, 81-101.

(2008), "Reflexões em torno da «presença mediterrânea» no Centro do território português, na charneira do Bronze para o Ferro", Contacto cultural entre el Mediterráneo y el Atlántico (siglos XII-VIII ane). La Precolonización a debate (S. Celestino, N. Rafel y X.L. Armada, Eds), Madrid, 371-400.

Ward, W.A. y Joukowsky, M.S., -Eds.-(1989), The Crisis Years:The $12^{\text {th }}$ Century B.C. From Beyond the Danube to the Tigris, Dubuque.

Weinstein, J. (1992), "The Collapse of the Egyptian Empire in the South Levant”, The Crisis Years: The $12^{\text {th }}$ Century B.C. From Beyong the Danube to the Tigris (W. Ward y M.S. Joukowsky, Eds.), Dubuque, 142-150.

Yadin, Y. (1958), "Solomon's City Wall and Gate at Gezer”, IEJ, 8, 80-86.

Yadin, Y. y Ben-Tor, A. (1993), "Hazor", The New Encyclopedia of Archaeological Excavations in the Holy Land, 2 (E. Stern, Ed.), Israel Exploration Society \& Carta, Jerusalén, 595. 